\title{
Bacterial load and cytokine profile in patients with cirrhosis following therapy with proton pump inhibitors: a prospective cohort study
}

\author{
Christos Triantos ${ }^{a}$, Maria Kalafatelia, Panagiota I. Spantideab ${ }^{b}$ Dimitrios Goukosc, \\ Efstratios Koutroumpakis ${ }^{a}$, Christos Konstantakis ${ }^{a}$, Stelios F. Assimakopoulos ${ }^{d}$, Charalambos Gogos ${ }^{d}$, \\ Athanasia Mouzaki ${ }^{b}$, Georgios Daikos ${ }^{c}$, Konstantinos Thomopoulos ${ }^{a}$ \\ University Hospital of Patras; Medical School, University of Patras; Laiko General Hospital, Athens, Greece
}

\begin{abstract}
Background The aim of this study was to explore the presence of bacterial products and the cytokine profile in outpatients with cirrhosis before and after short-term (4-8 weeks) administration of proton pump inhibitors (PPIs).

Methods Seventeen patients with cirrhosis-male/female: 12/5; age: median 59.2 years (49-65); etiology: HBV \pm HDV 23.5\%, HCV 17.7\%, alcohol 41.2\%, other $17.6 \%$; Child-Pugh score: median 7.5 (5-12); Model for End-stage Liver Disease: 10.5 (7-21); ascites (\%): 3 (17.7) —attending the outpatient clinics were included. None had hepatocellular carcinoma. Indications for PPIs were: esophagitis $(n=6,35.3 \%)$, peptic ulcer $(n=10,58.6 \%)$ and other $(n=1,5.9 \%)$. Bacterial DNA in serum and the levels of endotoxin, lipopolysaccharide binding protein, transforming growth factor- $\beta$, interleukin $-1 \beta,-6,-8,-12,-10$, tumor necrosis factor- $\alpha$ and nitric oxide were assessed at baseline (time 1) and at the end of treatment (time 2). The Wilcoxon signed rank test was used to evaluate significant differences in the parameters assayed before and after PPI administration.
\end{abstract}

Results No patients developed infection during the study period. Bacterial DNA was not detected before or after treatment. No significant differences were observed between the concentrations of any indices between times 1 and $2(\mathrm{P}>0.05)$. Subgroup analysis according to Child-Pugh stage yielded similar results.

Conclusion Short-term administration of PPIs had no effect on bacterial DNA, bacterial products or cytokine concentrations in patients with liver cirrhosis.

Keywords Bacterial translocation, cytokine profile, infection, liver cirrhosis, proton pump inhibitors

Ann Gastroenterol 2017; 30 (4): 1-7

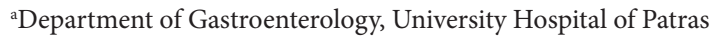
(Christos Triantos, Maria Kalafateli, Efstratios Koutroumpakis, Christos Konstantakis, Konstantinos Thomopoulos); ${ }^{\text {DDivision of }}$ Hematology, Department of Internal Medicine, Medical School, University of Patras (Panagiota Spadidea, Athanasia Mouzaki); 'Department of Propedeutic Medicine, Laiko General Hospital, Athens (Dimitrios Goukos, Georgios Daikos); ${ }^{\mathrm{d} D e p a r t m e n t ~ o f ~ I n t e r n a l ~}$ Medicine, University Hospital of Patras (Stelios Assimakopoulos, Charalambos Gogos), Greece

\section{Conflict of Interest: None}

Correspondence to: Christos Triantos, MD, D. Stamatopoulou 4, Rio 26504, Patras, Greece, e-mail: chtriantos@hotmail.com

Received 04 January 2017; accepted 08 March 2017 published online 06 April 2017

DOI: https://doi.org/10.20524/aog.2017.0142

\section{Introduction}

Liver cirrhosis is associated with a type of immune dysfunction referred to as cirrhosis-associated immune dysfunction syndrome [1]. Altered small bowel motility, small intestinal bacterial overgrowth and increased intestinal permeability lead to increased bacterial translocation and gut-related infections [2]. Bacterial infections influence hemodynamics [3] and coagulation status [4] and represent one of the most important reasons for the progression of liver failure, development of liver-related complications and mortality in patients with cirrhosis [5].

Proton pump inhibitors (PPIs) are widely used in patients with cirrhosis [6] because of the frequently observed mucosal abnormalities following screening endoscopy [7] and their use as prophylaxis for bleeding from post-banding esophageal 
ulcers [8]. Although there are data to suggest that PPIs increase the risk of infection [9-21], this positive association is not universal [22-24]. In a study of 607 consecutive patients with cirrhosis undergoing their first paracentesis at a tertiary center, the authors observed no association between PPIs and spontaneous bacterial peritonitis (SBP) or other infections, or mortality, suggesting that the severity of liver disease and other factors, rather than PPI treatment per se, may predispose to infectious complications [25]. Lastly, in a recent large, multicenter, prospective study, which included 519 patients with decompensated cirrhosis, PPI therapy was not found to be associated with a higher risk of SBP [26].

The interpretation of the published data is difficult because most of the studies were retrospective $[9,10,13-16,18,21,22,25]$, the use of PPIs was inappropriate in up to half of the patients [27], and the details about the duration of their administration before the diagnosis of the infection were unknown in many cases. We conducted this prospective study, in which we included patients with cirrhosis, with or without ascites, who underwent an upper gastrointestinal endoscopy and received "appropriate" treatment with PPIs, and we investigated the effect of PPIs on bacterial load and inflammatory cytokine production.

\section{Patients and methods}

This prospective cohort study was performed at the University Hospital of Patras (Patras, Greece) between February 2010 and October 2011. Patients with a previous history of SBP, liver transplantation, human immunodeficiency virus infection or any kind of immunosuppression, gastrointestinal bleeding, antibiotic prophylaxis during the last 2 weeks, hepatocellular carcinoma that exceeded the Milan criteria, portal vein thrombosis, and previous portosystemic shunt were excluded. We evaluated 45 consecutive patients with cirrhosis attending the hepatology outpatient clinic, who had no clinical, bacteriological or radiological signs of urinary tract, respiratory or systemic infection, and who underwent an upper gastrointestinal endoscopy. Finally, 17 patients were enrolled (15 patients received antibiotics during the last 2 weeks or after endoscopy, 2 had hepatocellular carcinoma that exceeded the Milan criteria and the others refused to participate in the study). Informed consent was obtained from all individual participants included in the study.

The characteristics of PPI use in terms of indication for administration, duration of therapy and the scheduled dose were recorded. "Appropriate" PPI use was defined as the use for the following indications: gastro-esophageal reflux disease, Helicobacter pylori (H. pylori) eradication, Barrett's esophagus, Zollinger-Ellison syndrome, prevention of nonsteroidal anti-inflammatory drug-induced ulcers, and peptic ulcer disease [28-32]. Prophylaxis following variceal band ligation was also considered "appropriate" for the purposes of this study [8]. None of the included patients had previously received PPI treatment. Time 1 was defined as baseline and time 2 concerned the length of PPI treatment, which ranged from 4-8 weeks. The study population was followed up after the end of PPI treatment for a median period of 14 months (12-17).

Cirrhosis was diagnosed based upon histological findings, clinical evaluation, laboratory data or imaging findings compatible with a diagnosis of cirrhosis [33]. The severity of liver disease was assessed by the Child-Pugh classification and the Model for End-stage Liver Disease (MELD) at baseline. In addition, routine clinical, biochemical and radiological analyses (abdominal ultrasound and/or computed tomography) were performed. The patients with alcoholic cirrhosis were abstinent for at least three months before their inclusion in this study. After baseline examination, patients were followed in the hepatology clinic at regular intervals according to current guidelines [33]. The presence of bacterial DNA in serum and the levels of endotoxin, transforming growth factor (TGF)- $\beta$, tumor necrosis factor (TNF)- $\alpha$, interleukin (IL) $-1 \beta,-6,-8,-10$, and $-12 p 70$, lipopolysaccharide binding protein (LBP) and nitric oxide (NOx) were assessed at baseline (time 1) and at the end (time 2) of treatment with PPIs.

\section{Determination of cytokine, LBP, endotoxin and NOx serum levels}

Peripheral blood samples (3-4 mL) from 17 cirrhotic patients were drawn before and after treatment with PPIs. Blood samples were centrifuged and the sera were collected and stored aliquoted at $-80^{\circ} \mathrm{C}$ until further use. The serum levels of cytokines IL- $1 \beta$, $-6,-8,-10,-12$ p70 and TNF- $\alpha$ were determined by a cytometric bead array method, using the Human Inflammatory Cytokine CBA kit (BD Bioscience, San Diego, USA). The measurements were performed on a BD FACS Array Bioanalyzer. The raw data were analyzed using the Flow Jo V7.5 software (Tree Star Inc., Ashland, OR, USA). Further analysis of the data was performed using the Curve Expert 1.4 software. Serum levels of TGF- $\beta$ and LBP were determined by ELISA, using a multispecies TGF- $\beta$ ELISA kit (Invitrogen Corporation, CA, USA) and a human LBP ELISA kit (SunRed Biological Technology, Shanghai). NOx levels were measured by a nitric oxide quantitation kit (Active Motif, Belgium). Endotoxin levels were measured using a LAL Chromogenic Endpoint assay (Hycult biotech, The Netherlands). Data analysis was performed using the Curve Expert 1.4 software. The detection limits of the methods employed were: IL- $8=3.6 \mathrm{pg} / \mathrm{mL}, \mathrm{IL}-1 \beta=7.2 \mathrm{pg} / \mathrm{mL}$, IL-6=2.5 pg/mL, IL-10=3.3 pg/mL, TNF- $\alpha=3.7 \mathrm{pg} / \mathrm{mL}$, IL$12 \mathrm{p} 70=1.9 \mathrm{pg} / \mathrm{mL}, \mathrm{LBP}=0.135 \mu \mathrm{g} / \mathrm{mL}, \mathrm{TGF}-\beta=15.6 \mathrm{pg} / \mathrm{mL}$, NOx $<1 \mu \mathrm{M}$, endotoxin $=0.04 \mathrm{EU} / \mathrm{mL}$.

\section{Bacterial DNA}

Bacterial DNA was detected as described previously [34]. Briefly, $400 \mu \mathrm{L}$ of human serum samples were centrifuged at $15,000 \mathrm{~g}$ for $15 \mathrm{~min}$. The supernatant was decanted and the remaining pellet was reconstituted in $1 \mathrm{~mL}$ of molecular biology grade water and centrifuged at $15,000 \mathrm{~g}$ for $10 \mathrm{~min}$. The supernatant was discarded and the pellet was again reconstituted in $40 \mu \mathrm{L}$ of molecular biology grade water 
followed by boiling in a water bath at $100^{\circ} \mathrm{C}$ for $10 \mathrm{~min}$. The mixture was then cooled on ice and centrifuged at 15,000 g for $10 \mathrm{sec} ; 2.5 \mu \mathrm{L}$ of the supernatant containing the bacterial DNA was used for subsequent PCR reactions. Amplification of a $540 \mathrm{bp}$ segment of the $16 \mathrm{~S}$ rRNA gene was performed with a pair of universal primers (F: 5'-AGAGTTTGATCATGGCTCAG-3', R: 5'-ACCGCGACTGCTGCTGGCAC-3') on a My Cycler thermal cycler (Biorad, USA) with $2.5 \mu \mathrm{L}$ of $10 \mathrm{x}$ PCR buffer, $0.75 \mu \mathrm{L}$ of $50 \mathrm{mM} \mathrm{MgCl} 2,2.0 \mu \mathrm{L}$ of $2.5 \mathrm{mM}$ each of dNTPS, $0.5 \mu \mathrm{L}$ of $25 \mu \mathrm{M}$ each primer and $0.625 \mathrm{U}$ of Recombinant DNA Taq Polymerase (Invitrogen, Carlsbad, CA, USA) in a total volume of $25 \mu \mathrm{L}$. The thermal conditions for the above reaction were as follows: 35 cycles of denaturation at $94^{\circ} \mathrm{C}$ for $30 \mathrm{sec}$, annealing at $55^{\circ} \mathrm{C}$ for $30 \mathrm{sec}$ and extension at $72^{\circ} \mathrm{C}$ for $1 \mathrm{~min}$. The amplicons were visualized on a $2 \%$ agarose gel stained with ethidium bromide under ultraviolet illumination.

\section{Statistical analysis}

Numerical data were expressed as mean \pm standard deviation if parametric or as median and range if non-parametric. The distribution of variables was tested for normality using the Kolmogorov-Smirnov test. Categorical data were expressed as counts and percentages and compared using the chisquare and Fisher's exact test. Continuous variables with and without normal distribution were compared using Student's $t$-test or the Mann-Whitney $U$ test, respectively. Spearman's correlation coefficient $(r)$ analysis was used for correlation of MELD score and cytokine/bacterial indices. The Wilcoxon signed rank test was used to evaluate significant differences in laboratory measurements before and after PPI administration. Significance testing was two-sided and set to $<0.05$. Analysis was performed using the SPSS statistical package (version 22.0, IBM, New York, NY, USA).

\section{Institutional review board statement}

The study was reviewed and approved by the Ethics committee of the University Hospital of Patras.

\section{Results}

\section{Baseline characteristics of study population}

Seventeen patients were included in the study. The majority were male (71\%) and the median age was 59 (49-65) years. The baseline demographic and clinical characteristics of the study participants are shown in Table 1 . None of the patients had hepatocellular carcinoma at baseline. The indications for PPI administration were esophagitis $(n=6,35.3 \%)$, peptic ulcer $(n=10,58.6 \%)$ and other $(n=1,5.9 \%)$. Bacterial DNA was not detected before the initiation of PPIs. The baseline median serum levels of bacterial products and cytokines are shown in Table 2.

\section{Correlation of cytokine and bacterial indices with the severity of liver disease}

Spearman's correlation analysis showed a positive, moderately strong correlation between MELD score and

$\underline{\text { Table } 1 \text { Baseline characteristics of the study population }}$

\begin{tabular}{lcc}
\hline & $\begin{array}{c}\text { N or } \\
\text { median }\end{array}$ & Percentage or range \\
\hline Age (years) & 59.2 & $49-65$ \\
Sex (M/F) & $12 / 5$ & $70.6 / 29.4$ \\
\hline Current smoking & 5 & 29.4 \\
\hline Etiology of liver disease & $7 / 4 / 3 / 2 / 1$ & $41.2 / 23.5 / 17.7 / 5.9 / 11.8$ \\
(alcohol/HBV/HCV/ & & \\
autoimmune/other) & & 52.9 \\
\hline -Blockers & 9 & $11.9-21$ \\
\hline PT (sec) & 14.65 & $1.06-1.87$ \\
INR & 1.2 & $0.7-1.5$ \\
\hline Creatinine (mg/dL) & 0.85 & $3.7-103$ \\
Urea (mg/dL) & 29.5 & $2.4-4.9$ \\
\hline Albumin (g/dL) & 3.8 & $0.67-11.15$ \\
\hline Total bilirubin (mg/dL) & 1.4 & $131-143$ \\
\hline Sodium (mmol/L) & 139.9 & 17.7 \\
\hline Ascites & 3 & 5.9 \\
\hline Encephalopathy & 1 & $5-12$ \\
CP score & 7.5 & $71.2 / 35.3 / 23.5$ \\
\hline CP class (A/B/C) & $7 / 6 / 4$ & $12-17$ \\
\hline MELD score & 10.5 & \\
\hline Months of follow up & 14 & \\
\hline & & \\
\hline
\end{tabular}

PT, prothrombin time; INR, international normalized ratio; CP, Child-Pugh; $M E L D$, model for end-stage liver disease

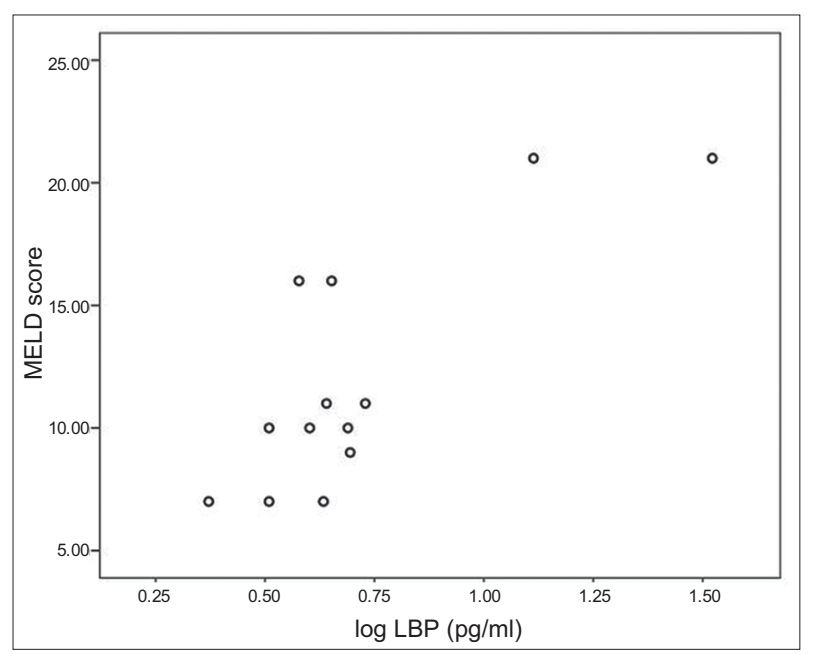

Figure 1 Scatter/dot plot presenting the correlation of baseline lipopolysaccharide binding protein (LBP) levels with Model for Endstage Liver Disease (MELD) score $(r=0.63, \mathrm{P}=0.02)$ 
Table 2 Serum levels of cytokines and bacterial products at baseline (Time 1) and following short-term PPI administration (Time 2)

\begin{tabular}{|c|c|c|c|c|}
\hline \multirow[t]{2}{*}{ Parameters measured } & \multicolumn{2}{|c|}{ Median (range) } & \multirow[t]{2}{*}{$\mathrm{Z}$ value } & \multirow[t]{2}{*}{$P$ value } \\
\hline & Time 1 & Time 2 & & \\
\hline Endotoxin $(\mathrm{EU} / \mathrm{mL})$ & $3.19(1.03-4.33)$ & $2.76(1.49-86.55)$ & -0.12 & 0.91 \\
\hline $\mathrm{LBP}(\mu \mathrm{g} / \mathrm{mL})$ & $4.08(3.23-12.99)$ & $4.65(0-17.53)$ & -0.414 & 0.68 \\
\hline $\mathrm{NOx}(\mu \mathrm{M})$ & $9.04(2.44-15.72)$ & $7.36(0.56-23.08)$ & -0.98 & 0.326 \\
\hline $\mathrm{TNFa}(\mathrm{pg} / \mathrm{mL})$ & $3.05(0-8.26)$ & $5.4(0-60.98)$ & -0.454 & 0.65 \\
\hline $\mathrm{TGFb}(\mathrm{ng} / \mathrm{mL})$ & $4.85(2.43-16.64)$ & $3.49(1.54-15.94)$ & -0.497 & 0.619 \\
\hline IL-1 (pg/mL) & $4.7(0-11.95)$ & $8.57(0-184.8)$ & -0.345 & 0.73 \\
\hline IL-6 (pg/mL) & $4.37(0-16.09)$ & $10.29(0-31.5)$ & -0.227 & 0.82 \\
\hline IL-12 (pg/mL) & $7.69(0-25.88)$ & $15.96(0-159)$ & -0.785 & 0.433 \\
\hline IL-10 (pg/mL) & $6.56(0-27.87)$ & $5.16(0-34.8)$ & -1.07 & 0.285 \\
\hline IL-8 (pg/mL) & $103.4(0-281.4)$ & $64.45(18.99-2892.4)$ & -0.308 & 0.758 \\
\hline
\end{tabular}

LBP, lipopolysaccharide binding protein; NOx, nitric oxide; TNF, tumor necrosis factor; TGF, tumor growth factor; IL, interleukin

baseline LBP ( $r=0.63, \mathrm{P}=0.02$ ) levels (Fig. 1), but no other correlations were observed. Child-Pugh score was not correlated with any of the evaluated indices. No differences were observed between patients with and without ascites (data not shown).

\section{Changes in the bacterial profile and cytokine concentrations following short-term PPI administration}

No patient developed infection during the study period. Bacterial DNA was not detected during the following 4-8 weeks of PPI treatment and the serum levels of cytokines and bacterial products were not significantly different from baseline (Table 2).

\section{Discussion}

We conducted this prospective study taking into consideration the need to use PPIs in patients with cirrhosis [35], the conflicting data in the literature [22-26], and the fact that only a few studies have examined the potential association between PPIs and a broad range of bacterial infections, with controversial results $[10,24]$. We found that the "appropriate" use of PPIs had no effect on serum bacterial DNA and other bacterial products, or on the cytokine profile of patients with cirrhosis.

In cirrhosis, the increased susceptibility to bacterial infections is related to a deficiency of bactericidal and opsonic activity, impaired monocyte function, depressed phagocytic activity of the reticuloendothelial system, defective chemotaxis, and low levels of complement in serum [36]. The clearance of translocated bacteria by the liver is inadequate because of the impaired reticuloendothelial cell phagocytosis and the increased collateral blood flow. Urinary tract infections, SBP, respiratory tract infections, and bacteremia are the most frequent bacterial infections seen in this setting.

Patients with liver cirrhosis rarely have normal endoscopic findings on upper gastrointestinal endoscopy [35]. In everyday clinical practice, there are several reasons for clinicians to consider the administration of PPIs in patients with liver cirrhosis, including abdominal discomfort related to ascites, dyspeptic symptoms associated with impaired small bowel motility, esophageal motor disorders, and finally, the misperception that gastroesophageal reflux contributes to variceal bleeding [27]. In a study by Tzathas et al [37], the authors suggested that $H$. pylori eradication does not protect all cirrhotics from ulcer recurrence and the majority of ulcers recur in $H$. pylori negative patients; therefore, omeprazole maintenance treatment is mandatory, irrespectively of $H$. pylori status. In addition there are data to support acid suppression therapy in the treatment of post-banding ulcers $[8,38]$.

Overuse of PPIs in this setting is well documented [27]. In the study of Bajaj et al [9], 47\% of patients receiving PPIs had no documented indication. In two other recent studies, the use of PPIs was inappropriate in $63 \%$ and $39.6 \%$ of cirrhotic patients [6], while in another prospective evaluation of intravenous PPI use, $56 \%$ of patients had no acceptable indication for their use [39]. In the Goel et al study, no documented indication was found in two thirds of the patients [13]. Finally, in another cohort of cirrhotic patients, PPIs were the most frequently prescribed drugs (67\%), often without a clear indication (59\%) [20]. In the same cohort, the use of $\beta$-blockers by cirrhotic patients had beneficial effects, reducing the prevalence of infections and improving the patient's outcome when an infection occurred [20]. Moreover, other studies indicate that the reduction of hepatic venous pressure gradient was independently associated with a decreased risk of SBP or bacteremia $[40,41]$. In the current study, nine patients were on $\beta$-blockers and none of them discontinued their administration before inclusion in the study. In this study we used paired samples; thus, propranolol administration does not impair our results. 
Use of PPIs has been related to infections because of hypochlorhydria, impaired gastrointestinal motility [17] and neutrophil functioning [22], decreased granulocyte and monocyte oxidative burst [42], increased intestinal paracellular permeability [43] and direct effects on the immune system [9]. Small intestinal bacterial overgrowth following PPI use has been reported in both animal and human studies [44]. However, there are methodological issues, because some were single-center studies that had small sample sizes $[9,11,13]$ and mainly included hospitalized patients with ascites $[9,11,22]$. In addition, most published studies did not report the duration of exposure to PPIs, so the positive association could be related to possible bias [14]. The abovementioned limitations make the interpretation of these results difficult.

In the present study, none of our patients developed an overt infection during the follow-up period. Most importantly, no differences in the bacterial load and the cytokine profile were observed over time, implying that none developed a subclinical infection. Cirrhosis-associated immune dysfunction syndrome is related to both immunodeficiency and production of proinflammatory cytokines. Immunodeficiency affects both the innate and the adaptive arm of the immune system [5]. Systemic inflammatory response syndrome has been described in $57-70 \%$ of infected patients with liver cirrhosis [45]. Bacterial-derived products, such as peptidoglycans and lipopolysaccharides, bind to toll-like receptors and stimulate the release of NOx and proinflammatory cytokines such as TNF- $\alpha$, IL-1 and IL-6. In systemic inflammatory response syndrome, anti-inflammatory cytokines are unable to counterbalance the increased production of proinflammatory cytokines [1].

We measured LBP, a protein with a relatively long halflife synthesized by the liver in response to bacteremia and bacterial DNA [46], considering the various limitations that accompany the use of endotoxin for the detection of infection in cirrhosis. We observed no differences in the concentrations of the proinflammatory cytokines TNF- $\alpha$, IL-1, IL-6, IL- 8 and IL-12p70, the anti-inflammatory cytokines IL-10 and TGF- $\beta$, endotoxin, LBP and NOx, before and after PPI administration. These results indicate an absence of subclinical infections over time in our cohort.

In addition, we did not detect bacterial DNA in our patients. These results are in disagreement with previous studies that reported the presence of bacterial DNA in both ascitic fluid and blood of $30-40 \%$ of hospitalized patients with cirrhosis and culture-negative non-neutrocytic ascites [47]. To date, detectable bacterial DNA has been reported as an indicator of poor prognosis [48]. However, our data is in line with a study by Vlachogiannakos et al [34], where bacterial DNA was not detected in the blood samples of 30 patients with cirrhosis who had ascites, even though endotoxemia was common in this cohort of patients and correlated with the severity of liver disease. In addition, in the Sersté et al study [49], 31 asymptomatic outpatients with cirrhosis and non-neutrocytic ascites (54.8\% Child-Pugh C), who underwent therapeutic paracentesis in an outpatient clinic (18 patients had several consecutive paracenteses), were tested for the presence of bacterial DNA. The test was negative in the majority of the patients (28/31). The authors concluded that bacterial DNA is rarely detected in serum and ascitic fluid of outpatients with cirrhosis and non-neutrocytic ascites, and the strength of this observation is that a number of patients underwent repeated paracentesis. Discrepancies between the results in different reports may be due to the inclusion of patients who were admitted to hospital for complications of cirrhosis, possibly associated with enhanced bacterial translocation [50]. Another possible explanation for not detecting bacterial DNA in our patients is that transient episodes of bacterial translocation could have been missed, as we only monitored twice for bacterial DNA. Lastly, we included only $18 \%$ patients with ascites, as some report that serum bacterial DNA is present only in cirrhotics with ascites [51]. However, our results seem to be consistent with the low prevalence of SBP reported in outpatient-based series [50].

The non-randomized design and the small sample size are limitations of this study. However, we prospectively followed our patients with or without ascites and we extensively [46] investigated the presence of either an overt or a subclinical infection.

In conclusion, in this cohort, short-term PPI administration had no effect either on cytokine concentrations or bacterial

\section{Summary Box}

\section{What is already known:}

- Bacterial infections influence hemodynamics and coagulation status and constitute one of the most important reasons for the progression of liver failure, development of liver-related complications and mortality in patients with cirrhosis

- There are data suggesting that the use of proton pump inhibitors (PPIs) is associated with bacterial infections in patients with liver cirrhosis

\section{What the new findings are:}

- There is a positive correlation between Model for End-stage Liver Disease score and baseline lipopolysaccharide binding protein (LBP) levels in patients with liver cirrhosis

- Short-term PPI administration does not affect the concentrations of the proinflammatory cytokines tumor necrosis factor- $\alpha$, interleukin $-1,-6,-8$ and -12 p70, or the anti-inflammatory cytokines IL-10 and transforming growth factor- $\beta$, or the levels of endotoxin, LBP and nitric oxide

- Short-term PPI administration has no effect on the bacterial load of cirrhotic patients

- There is no association between "appropriate" PPI treatment and the development of subclinical infection in cirrhotic patients 
load in patients with cirrhosis, suggesting that the "appropriate use" of PPIs is safe in this setting. However, larger studies with longer follow up are needed to confirm the safety of the longterm use of PPIs, especially in patients with advanced liver disease.

\section{References}

1. Bonnel AR, Bunchorntavakul C, Reddy KR. Immune dysfunction and infections in patients with cirrhosis. Clin Gastroenterol Hepatol 2011;9:727-738.

2. Gupta A, Dhiman RK, Kumari S, et al. Role of small intestinal bacterial overgrowth and delayed gastrointestinal transit time in cirrhotic patients with minimal hepatic encephalopathy. J Hepatol 2010;53:849-855.

3. Rasaratnam B, Kaye D, Jennings G, Dudley F, Chin-Dusting J. The effect of selective intestinal decontamination on the hyperdynamic circulatory state in cirrhosis. A randomized trial. Ann Intern Med 2003;139:186-193.

4. Montalto P, Vlachogiannakos J, Cox DJ, Pastacaldi S, Patch D, Burroughs AK. Bacterial infection in cirrhosis impairs coagulation by a heparin effect: a prospective study. J Hepatol 2002:37:463-470.

5. Jalan R, Fernandez J, Wiest R, et al. Bacterial infections in cirrhosis: a position statement based on the EASL Special Conference 2013. J Hepatol 2014;60:1310-1324.

6. Kalaitzakis E, Björnsson E. Inadequate use of proton-pump inhibitors in patients with liver cirrhosis. Eur $J$ Gastroenterol Hepatol 2008;20:512-518.

7. Garcia-Tsao G, Sanyal AJ, Grace ND, Carey W; Practice Parameters Committee of the American College of Gastroenterology. Prevention and management of gastroesophageal varices and variceal hemorrhage in cirrhosis. Hepatology 2007;46:922-938.

8. Shaheen NJ, Stuart E, Schmitz SM, et al. Pantoprazole reduces the size of postbanding ulcers after variceal band ligation: a randomized, controlled trial. Hepatology 2005;41:588-594.

9. Bajaj JS, Zadvornova Y, Heuman DM, et al. Association of proton pump inhibitor therapy with spontaneous bacterial peritonitis in cirrhotic patients with ascites. Am J Gastroenterol 2009;104:1130-1134.

10. Bajaj JS, Ratliff SM, Heuman DM, Lapane KL. Proton pump inhibitors are associated with a high rate of serious infections in veterans with decompensated cirrhosis. Aliment Pharmacol Ther 2012;36:866-874.

11. Choi EJ, Lee HJ, Kim KO, et al. Association between acid suppressive therapy and spontaneous bacterial peritonitis in cirrhotic patients with ascites. Scand J Gastroenterol 2011;46:616-620.

12. Deshpande A, Pasupuleti V, Thota P, et al. Acid-suppressive therapy is associated with spontaneous bacterial peritonitis in cirrhotic patients: a meta-analysis. J Gastroenterol Hepatol 2013;28:235-242.

13. Goel GA, Deshpande A, Lopez R, Hall GS, van Duin D, Carey WD. Increased rate of spontaneous bacterial peritonitis among cirrhotic patients receiving pharmacologic acid suppression. Clin Gastroenterol Hepatol 2012;10:422-427.

14. Kwon JH, Koh SJ, Kim W, et al. Mortality associated with proton pump inhibitors in cirrhotic patients with spontaneous bacterial peritonitis. J Gastroenterol Hepatol 2014;29:775-781.

15. Miura K, Tanaka A, Yamamoto T, Adachi M, Takikawa H. Proton pump inhibitor use is associated with spontaneous bacterial peritonitis in patients with liver cirrhosis. Intern Med 2014;53:1037-1042.

16. Ratelle M, Perreault S, Villeneuve JP, Tremblay L. Association between proton pump inhibitor use and spontaneous bacterial peritonitis in cirrhotic patients with ascites. Can J Gastroenterol Hepatol 2014;28:330-334.

17. Trikudanathan G, Israel J, Cappa J, O'Sullivan DM. Association between proton pump inhibitors and spontaneous bacterial peritonitis in cirrhotic patients - a systematic review and metaanalysis. Int J Clin Pract 2011;65:674-678.

18. Min YW, Lim KS, Min BH, et al. Proton pump inhibitor use significantly increases the risk of spontaneous bacterial peritonitis in 1965 patients with cirrhosis and ascites: a propensity score matched cohort study. Aliment Pharmacol Ther 2014;40:695-704.

19. O'Leary JG, Reddy KR, Wong F, et al; North American Consortium for the Study of End-Stage Liver Disease. Long-term use of antibiotics and proton pump inhibitors predict development of infections in patients with cirrhosis. Clin Gastroenterol Hepatol 2015;13:753-759.e1-e2.

20. Merli M, Lucidi C, Di Gregorio V, et al. The chronic use of betablockers and proton pump inhibitors may affect the rate of bacterial infections in cirrhosis. Liver Int 2015;35:362-369.

21. Sargenti K, Prytz H, Strand A, Nilsson E, Kalaitzakis E. Healthcareassociated and nosocomial bacterial infections in cirrhosis: predictors and impact on outcome. Liver Int 2015;35:391-400.

22. Campbell MS, Obstein K, Reddy KR, Yang YX. Association between proton pump inhibitor use and spontaneous bacterial peritonitis. Dig Dis Sci 2008;53:394-398.

23. de Vos M, De Vroey B, Garcia BG, et al. Role of proton pump inhibitors in the occurrence and the prognosis of spontaneous bacterial peritonitis in cirrhotic patients with ascites. Liver Int 2013;33:1316-1323.

24. van Vlerken LG, Huisman EJ, van Hoek B, et al. Bacterial infections in cirrhosis: role of proton pump inhibitors and intestinal permeability. Eur J Clin Invest 2012;42:760-767.

25. Mandorfer M, Bota S, Schwabl P, et al. Proton pump inhibitor intake neither predisposes to spontaneous bacterial peritonitis or other infections nor increases mortality in patients with cirrhosis and ascites. PLoS One 2014;9:e110503.

26. Terg R, Casciato P, Garbe C, et al; Study Group of Cirrhosis Complications of the Argentine Association for the Study of Liver Disease. Proton pump inhibitor therapy does not increase the incidence of spontaneous bacterial peritonitis in cirrhosis: a multicenter prospective study. J Hepatol 2015;62:1056-1060.

27. Lodato F, Azzaroli F, Di Girolamo M, et al. Proton pump inhibitors in cirrhosis: tradition or evidence based practice? World $J$ Gastroenterol 2008;14:2980-2985.

28. Kahrilas PJ, Shaheen NJ, Vaezi MF; Clinical Practice and Quality Management Committee. American Gastroenterological Association Institute technical review on the management of gastroesophageal reflux disease. Gastroenterology 2008;135:1392-1413.

29. Laine L, Jensen DM. Management of patients with ulcer bleeding. Am J Gastroenterol 2012;107:345-360; quiz 361.

30. Lanza FL, Chan FK, Quigley EM; Practice Parameters Committee of the American College of Gastroenterology. Guidelines for prevention of NSAID-related ulcer complications. Am J Gastroenterol 2009;104:728-738.

31. Malfertheiner P, Chan FK, McColl KE. Peptic ulcer disease. Lancet 2009;374:1449-1461.

32. Spechler SJ, Sharma P, Souza RF, Inadomi JM, Shaheen NJ; American Gastroenterological Association. American Gastroenterological Association technical review on the management of Barrett's esophagus. Gastroenterology 2011;140:e18-e52; quiz e13.

33. Garcia-Tsao G, Lim JK, Lim J; Members of Veterans Affairs Hepatitis C Resource Center Program. Management and treatment of patients with cirrhosis and portal hypertension: recommendations from the Department of Veterans Affairs Hepatitis C Resource Center Program and the National Hepatitis C Program. Am J Gastroenterol 2009;104:1802-1829. 
34. Vlachogiannakos J, Daikos G, Thalheimer U, Burroughs AK, Ladas SD. Is bacterial DNA a better marker than endotoxin of bacterial translocation in decompensated cirrhosis? Hepatology 2011;53:2140-2141.

35. Rabinovitz M, Yoo YK, Schade RR, Dindzans VJ, Van Thiel DH, Gavaler JS. Prevalence of endoscopic findings in 510 consecutive individuals with cirrhosis evaluated prospectively. Dig Dis Sci 1990;35:705-710.

36. Thalheimer U, Triantos CK, Samonakis DN, Patch D, Burroughs AK. Infection, coagulation, and variceal bleeding in cirrhosis. Gut 2005;54:556-563.

37. Tzathas C, Triantafyllou K, Mallas E, Triantafyllou G, Ladas SD. Effect of Helicobacter pylori eradication and antisecretory maintenance therapy on peptic ulcer recurrence in cirrhotic patients: a prospective, cohort 2 -year follow-up study. $J$ Clin Gastroenterol 2008;42:744-749.

38. Hidaka H, Nakazawa T, Wang G, et al. Long-term administration of PPI reduces treatment failures after esophageal variceal band ligation: a randomized, controlled trial. J Gastroenterol 2012;47:118-126.

39. Guda NM, Noonan M, Kreiner MJ, Partington S, Vakil N. Use of intravenous proton pump inhibitors in community practice: an explanation for the shortage? Am J Gastroenterol 2004;99:1233-1237.

40. Turnes J, Garcia-Pagan JC, Abraldes JG, Hernandez-Guerra M, Dell'Era A, Bosch J. Pharmacological reduction of portal pressure and long-term risk of first variceal bleeding in patients with cirrhosis. Am J Gastroenterol 2006;101:506-512.

41. Senzolo M, Cholongitas E, Burra P, et al. beta-Blockers protect against spontaneous bacterial peritonitis in cirrhotic patients: a meta-analysis. Liver Int 2009;29:1189-1193.

42. Garcia-Martinez I, Francés R, Zapater P, et al. Use of proton pump inhibitors decrease cellular oxidative burst in patients with decompensated cirrhosis. J Gastroenterol Hepatol 2015;30:147-154.

43. Hopkins AM, McDonnell C, Breslin NP, O’Morain CA, Baird AW. Omeprazole increases permeability across isolated rat gastric mucosa pre-treated with an acid secretagogue. J Pharm Pharmacol 2002;54:341-347.

44. Parkman HP, Urbain JL, Knight LC, et al. Effect of gastric acid suppressants on human gastric motility. Gut 1998;42:243-250.

45. Le Moine O, Marchant A, De Groote D, Azar C, Goldman M, Devière J. Role of defective monocyte interleukin-10 release in tumor necrosis factor-alpha overproduction in alcoholics cirrhosis. Hepatology 1995;22:1436-1439.

46. Bellot P, Francés R, Such J. Pathological bacterial translocation in cirrhosis: pathophysiology, diagnosis and clinical implications. Liver Int 2013;33:31-39.

47. Such J, Francés R, Muñoz C, et al. Detection and identification of bacterial DNA in patients with cirrhosis and culture-negative, nonneutrocytic ascites. Hepatology 2002;36:135-141.

48. Zapater P, Francés R, González-Navajas JM, et al. Serum and ascitic fluid bacterial DNA: a new independent prognostic factor in noninfected patients with cirrhosis. Hepatology 2008;48:1924-1931.

49. Sersté T, Bert F, Leflon-Guibout V, et al. Detection of bacterial DNA in serum and ascitic fluid of asymptomatic outpatients with cirrhosis and non-neutrocytic ascites. Liver Int 2011;31:494-498.

50. Sersté T, Bert F, Leflon-Guibout V, et al. 854 bacterial DNA is rarely detected in the serum and the ascitic fluid of noninfected outpatients with cirrhosis and ascites treated by paracentesis. J Hepatol 2010;52:S332-S333.

51. Bellot P, García-Pagán JC, Francés R, et al. Bacterial DNA translocation is associated with systemic circulatory abnormalities and intrahepatic endothelial dysfunction in patients with cirrhosis. Hepatology 2010;52:2044-2052. 